\title{
Erratum to: Threshold temperatures mediate the impact of reduced snow cover on overwintering freeze tolerant caterpillars
}

\author{
Katie E. Marshall $\cdot$ Brent J. Sinclair
}

Published online: 4 January 2012

(C) Springer-Verlag 2011

\section{Erratum to: Naturwissenschaften}

\section{DOI 10.1007/s00114-011-0866-0}

\begin{abstract}
A typesetting error resulted in incorrect labels on the vertical axes of Figure 3. " 451 " should read " 160 " in all three panels and "910" should read "210" in Figure 3b. The corrected figure is shown below. This error does not affect any of the results or conclusions of the paper.
\end{abstract}

Communicated by: Sven Thatje

The online version of the original article can be found at http:// dx.doi.org/10.1007/s00114-011-0866-0.

K. E. Marshall $(\bowtie) \cdot$ B. J. Sinclair

Department of Biology, The University of Western Ontario,

London, ON, Canada N6G 1L3

e-mail: kmarsh32@uwo.ca 

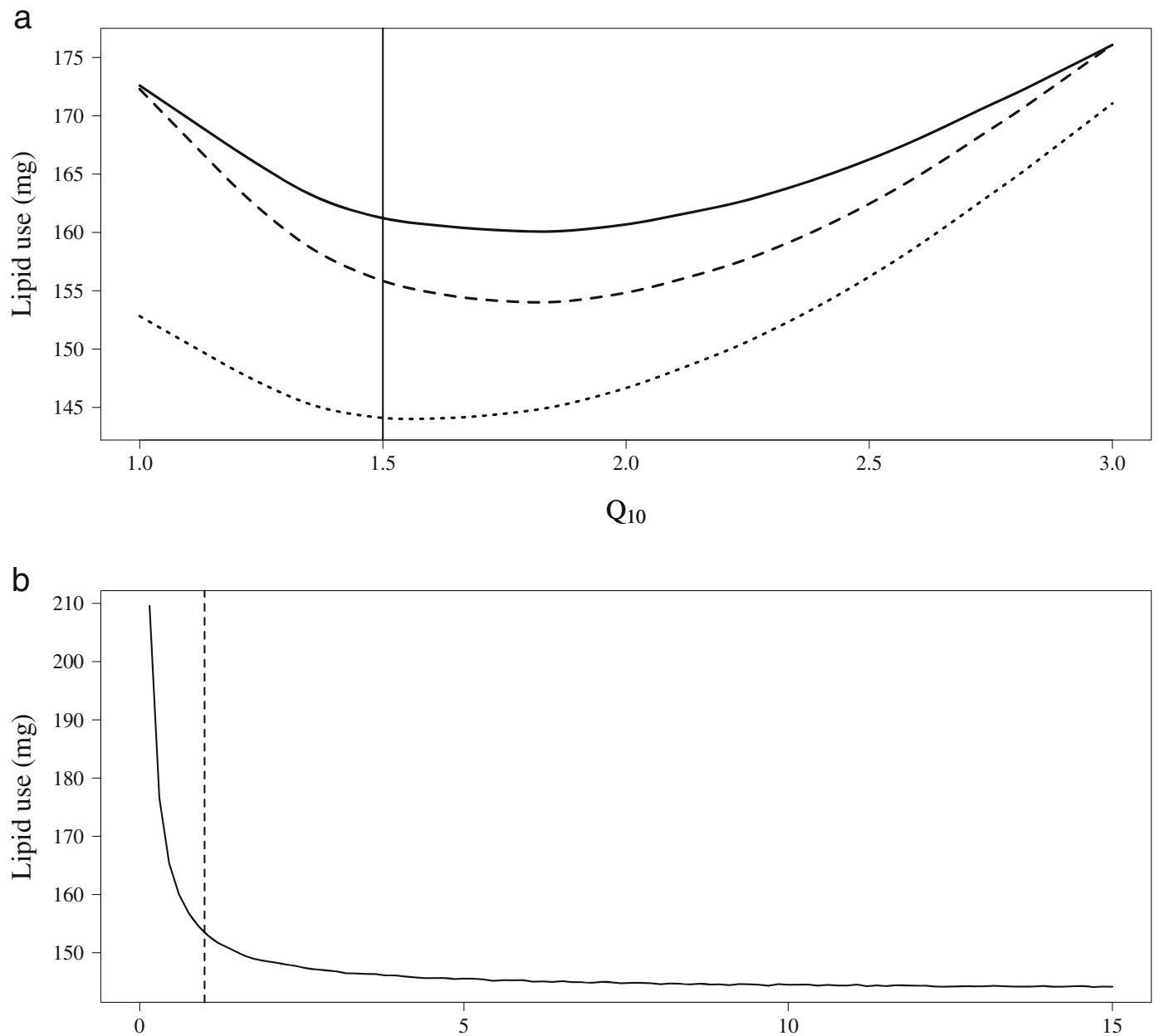

Freezing depression factor

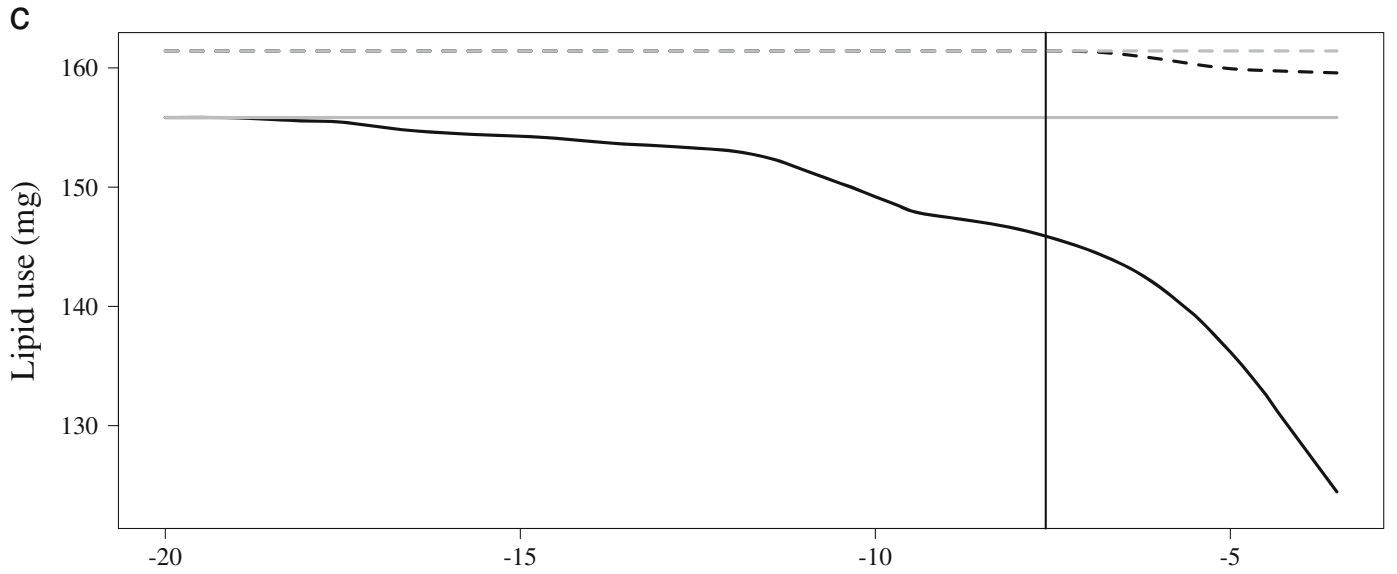

Freezing point $\left({ }^{\circ} \mathrm{C}\right)$

Fig. 3 a Sensitivity of model predicting overwintering energy use (in $\mathrm{mg}$ lipid) by $P$. isabella to changes in temperature sensitivity (in $\mathrm{Q}_{10}$ values) in the subnivean microclimate (solid line), exposed but not accounting metabolic depression during freezing (dashed line), or exposed and accounting for metabolic depression during freezing (dotted line). Vertical line indicates the $\mathrm{Q}_{10}$ value used in the final simulation (Fig. 2). b Sensitivity of model predicting overwintering energy use (in mg lipid) by $P$. isabella in the exposed microclimate to changes in the amount of metabolic depression by freezing. Vertical line indicates a freezing depression factor of 1 (i.e. no change with freezing). c Sensitivity of model predicting overwintering energy use (in mg lipid) by P. isabella both above (solid lines) and below (dashed lines) the snow layer either including (black lines) or not including (grey lines) metabolic depression of freezing to changes in freezing point. The freezing point of $P$. isabella as measured in the laboratory (Marshall and Sinclair 2011) is represented by a solid vertical line 